\title{
The role of heterogeneous lithology in a glaciofluvial deposit on unsaturated preferential flow - a numerical study
}

\author{
Erij Ben Slimene ${ }^{1}$, Laurent Lassabatere ${ }^{1 *}$, Jiřr Šimůnek ${ }^{2}$, Thierry Winiarski ${ }^{1}$, Remy Gourdon ${ }^{3}$ \\ ${ }^{1}$ Université de Lyon, Laboratoire d'Ecologie des Hydrosystèmes Naturels et Anthropisés, LEHNA, UMR 5023 CNRS, ENTPE, \\ UCB-Lyon-1, Rue Maurice Audin, 69518 Vaulx-en-Velin, France. \\ ${ }^{2}$ Department of Environmental Sciences, University of California Riverside, Riverside, CA, USA. \\ E-mail: Jiri.Simunek@ucr.edu \\ ${ }^{3}$ Université de Lyon, INSA-Lyon, LGCIE-DEEP, 20 Av. Albert Einstein, F-69621 Villeurbanne cedex, France. \\ ${ }^{*}$ Corresponding author. E-mail: laurent.lassabatere@entpe.fr
}

\begin{abstract}
An understanding of preferential flow in the vadose zone is crucial for the prediction of the fate of pollutants. Infiltration basins, developed to mitigate the adverse effects of impervious surfaces in urban areas, are established above strongly heterogeneous and highly permeable deposits and thus are prone to preferential flow and enhanced pollutant transport. This study numerically investigates the establishment of preferential flow in an infiltration basin in the Lyon suburbs (France) established over a highly heterogeneous glaciofluvial deposit covering much of the Lyon region. An investigation of the soil transect (13.5 m long and $2.5 \mathrm{~m}$ deep) provided full characterization of lithology and hydraulic properties of present lithofacies. Numerical modeling with the HYDRUS-2D model of water flow in the transect was used to identify the effects of individual lithofacies that constitute the deposit. Multiple scenarios that considered different levels of heterogeneity were evaluated. Preferential flow was studied for several values of infiltration rates applied after a long dry period. The numerical study shows that the high contrast in hydraulic properties of different lithofacies triggers the establishment of preferential flow (capillary barriers and funneled flow). Preferential flow develops mainly for low water fluxes imposed at the surface. The role of individual lithofacies in triggering preferential flow depends on their shapes (layering versus inclusions) and their sizes. While lenses and inclusions produce preferential flow pathways, the presence of the surface layer has no effect on the development of preferential flow and it only affects the effective hydraulic conductivity of the heterogeneous transect.
\end{abstract}

Keywords: Preferential flow; Heterogeneity; Lithology; Numerical modeling; Soil hydraulic properties; Boundary conditions; HYDRUS-2D.

\section{INTRODUCTION}

Field and laboratory studies have demonstrated that preferential flow in the vadose zone is more a rule than the exception (Köhne et al., 2009a). Preferential flow can be seen as uneven and rapid movement of water and solutes through certain zones of the porous media, while any remaining water is quasistagnant. Preferential flow can be caused by multiple physical or chemical factors such as hydrophobicity, macropores, or hydraulic instability. Similar types of flow have also been related to heterogeneous lithology, specifically in heterogeneous soils and deposits that are formed by lithofacies with contrasting properties. Preferential flow is considered to be an important process since it is expected to enhance the transport of nutrients, pollutants, and bacterial pathogens (e.g., Jarvis, 2007; Köhne et al., 2009a, 2009b) by bypassing soil reactive particles and thus limiting the storage, filtering, and buffering functions of soils (e.g., Clothier et al., 1992). It is crucial to understand flow processes that trigger the establishment of preferential flow and to identify hydraulic conditions prone to preferential flow.

Infiltration basins are highly suitable for studying the establishment of preferential flow. Infiltration basins are ecotechnological structures designed to mitigate the impact of increased stormwater runoff from urban areas by infiltrating runoff water directly into the ground. To ensure their infiltration function, these structures are usually established over highly permeable and strongly heterogeneous soils. Preferential flow can thus easily develop in these soils and impact pollutant transport. When instrumented to monitor flow and transport, these sites can serve as a field laboratory for the study of preferential flow and its impact on solute transport.

Modeling preferential flow in infiltration basins is a special case of modeling preferential flow in the vadose zone. Modeling of preferential flow has been conducted for many different purposes in order to improve the understanding of the water cycle and the fate of pollutants in soils (e.g., Allaire et al., 2009; Köhne et al., 2009a, 2009b). Many different models, such as the dual-porosity and dual-permeability non-equilibrium models (Šimůnek et al., 2003), have been developed to simulate preferential flow and transport during various hydrological processes, including water infiltration (e.g. Lassabatere et al., 2014). Modeling approaches at the macroscopic scale are most often based on the use of the Richards equation and can consider the spatial variability of hydraulic and transport properties of the soil (e.g., Birkholzer and Tsang, 1997). For strongly heterogeneous deposits and soils, different lithofacies with different shapes of inclusions and layers can be defined in a numerical transport domain, and flow can be modeled using the knowledge of the hydraulic properties of the lithofacies (e.g., Coutinho et al., 2015). However, to the authors' knowledge, no studies have clearly identified the role of individual lithofacies, inclusions, or layers in heterogeneous soils on preferential flow. Also, their roles have never been studied as functions of the infiltration rate at the soil surface or as functions of the degree of saturation, although it is well known that the degree of saturation is a key factor for the establishment of preferential flow, such as funneled flow, induced by lithological heterogeneities. 
In this paper, we model the establishment of preferential flow during infiltration in an infiltration basin involving a strongly heterogeneous deposit made of lithofacies with contrasting hydraulic properties and different shapes (layers and inclusions). Preferential flow is modeled at the scale of a soil transect $13.5 \mathrm{~m}$ long and $2.5 \mathrm{~m}$ deep, accounting for lithological heterogeneity and considering a fixed flow rate imposed at the surface. The establishment of preferential flow is depicted for both transient and steady state conditions. This work focuses on the influence of individual lithofacies and their shapes (inclusions versus layers) on flow heterogeneity at several flow rates imposed at the soil surface, thus mimicking rainfall events with different rainfall intensities.

\section{MATERIALS AND METHODS Studied infiltration basin}

The Django Reinhardt infiltration basin is located at Chassieu, in the suburbs of Lyon, France. It covers $13,775 \mathrm{~m}^{2}$ and receives stormwater from an urban industrialized watershed of 185 ha (Winiarski et al., 2006). It was directly set up above the heterogeneous glaciofluvial deposit by mixing the top 50-80 $\mathrm{cm}$ of the soil (Goutaland et al., 2008; Winiarski et al., 2006). The vadose zone is approximately $13 \mathrm{~m}$ deep (an average depth to groundwater). Two trenches were dug in the infiltration basin, with excavation being conducted by a mechanical shovel.

The excavation was followed by a sedimentological study that provided the detailed description of the soil profile beneath the soil surface. The sedimentological study (Fig. 1a) showed that the glaciofluvial deposit is composed of four main lithofacies: (i) the upper layer that is a mixture of the soil matrix and gravel, (ii) a mixture of the soil matrix and gravel that has a bimodal particle size distribution (PSD) and occupies most of the deposit below the top 50-80 cm layer, (iii) large lenses of sand, and (iv) smaller lenses of matrix-free gravel (Goutaland et al., 2008). These lithofacies are referred to as Gravel with matrix (or the upper layer), Bimodal Gravel, Sand, and Gravel, respectively. These four materials were characterized with regards to their water retention and hydraulic conductivity curves (Goutaland et al., 2013; Lassabatere et al., 2010) using water infiltration experiments and the BEST method (Lassabatere et al., 2006). The lithofacies exhibit contrasting properties (Fig. 1b) and can be sorted with regards to their hydraulic conductivity (a decreasing order) and water retention (an increasing order): Gravel $>$ Sand $>$ Gravel with matrix $>$ Bimodal gravel. As expected, the lithofacies that exhibit the largest values of the saturated hydraulic conductivity exhibit at the same time the lowest water retention. The contrast in hydraulic properties between Gravel and Sand, on the one hand, and the predominant lithofacies Bimodal Gravel, on the other hand, is expected to favor funneled flow (Walter et al., 2000).

\section{Numerical model}

Modeling of water flow was carried out using the HYDRUS2D model (Šimůnek and van Genuchten, 2008; Šimůnek et al., 2008, 2016) that numerically solves the generalized Richards equation, which is based on the combination of the DarcyBuckingham law and the mass conservation equation (Hillel, 1998).

$$
\frac{\partial \theta}{\partial t}=\nabla .(K(\theta) \nabla H)
$$

$H=z+h$ where $\theta\left(\mathrm{L}^{3} \mathrm{~L}^{-3}\right)$ is the volumetric water content, $x(\mathrm{~L})$ and $z(\mathrm{~L})$ are the spatial coordinates, $h(\mathrm{~L})$ is the water pressure head, $t$ (T) is time, and $K\left(\mathrm{~L} \mathrm{~T}^{-1}\right)$ is the unsaturated hydraulic conductivity tensor, which depends on the water content, $\theta$. The solution of equations (1) requires knowledge of the water retention and hydraulic conductivity functions, $h(\theta)$ and $K(\theta)$, respectively, in addition to the knowledge of boundary and initial conditions. In this study, we used the water retention and hydraulic conductivity functions as estimated by Goutaland et al. (2013), considering the van Genuchten relation (van Genuchten, 1980) in conjunction with the Mualem capillary model (Mualem, 1976):

$S_{e}(h)=\left(1+\left(\frac{h}{h_{g}}\right)^{n}\right)^{-m}$

$K\left(S_{e}\right)=K_{s} S_{e}^{l}\left(1-\left(1-S_{e}^{1 / m}\right)^{m}\right)^{2}$

$m=1-\frac{1}{n}$

$S_{e}=\frac{\theta-\theta_{r}}{\theta_{s}-\theta_{r}}$

where $S_{e}(-)$ is the degree of saturation, $h_{g}(\mathrm{~L}), n(-), m(-)$, and $l(-)$ are hydraulic shape parameters, $\theta_{r}\left(\mathrm{~L}^{3} \mathrm{~L}^{-3}\right)$ and $\theta_{s}\left(\mathrm{~L}^{3} \mathrm{~L}^{-3}\right)$ are the residual and saturated volumetric water contents, respectively, and $K_{s}\left(\mathrm{~L}^{3} \mathrm{~T}^{-1}\right)$ is the saturated hydraulic conductivity. The lithofacies were assigned the hydraulic properties as shown in Fig. $1 \mathrm{~b}$.

The transect was represented by a two-dimensional flow domain $13.5 \mathrm{~m}$ long and $2.5 \mathrm{~m}$ deep. The flow domain was discretized using unstructured triangular elements with 18,500 nodes (Fig. 1a). The lower boundary was assigned a free drainage boundary condition and vertical sides were assigned no flux conditions. The entire transect was initially set at a water pressure head of $-0.1 \mathrm{~m}$ to ensure almost full saturation and then allowed to drain for $168 \mathrm{~h}$. The water pressure heads at $168 \mathrm{~h}$ were then used as initial conditions for the infiltration experiment. The transect was subjected to the target infiltration rate at the soil surface. Numerically, the upper boundary condition was assigned an atmospheric boundary condition with no evaporation and constant precipitation as often considered when modeling water infiltration in soils (Šimůnek et al., 2008). Several values of precipitation rates were imposed between 0.0025 and $0.04 \mathrm{~m} / \mathrm{h}$, corresponding to a range of final hydrological states between "very dry" and close to saturation. These values were lower than saturated hydraulic conductivities of lithofacies, ensuring full infiltration of water into the profile and no runoff at the surface. These values were selected in agreement with incoming water fluxes measured in the retention pond located upstream of the infiltration basin (data not shown).

The role of lithofacies on flow heterogeneity was investigated for the following scenarios with different levels of heterogeneity (Fig. 1c). A control run (Scenario 1) denoted as "Hom" assumed a homogeneous soil profile consisting of a predominant lithofacies, i.e., bimodal gravel. The following five scenarios considered different levels of heterogeneity by defining additional soil layers and inclusions in the homogeneous transect. Scenario 2, denoted as "Layer," additionally considered a surface layer of gravel with matrix. Scenario 3, denoted as "All," additionally considered all lithofacies and heterogeneities. 
a) Trench and lithological study

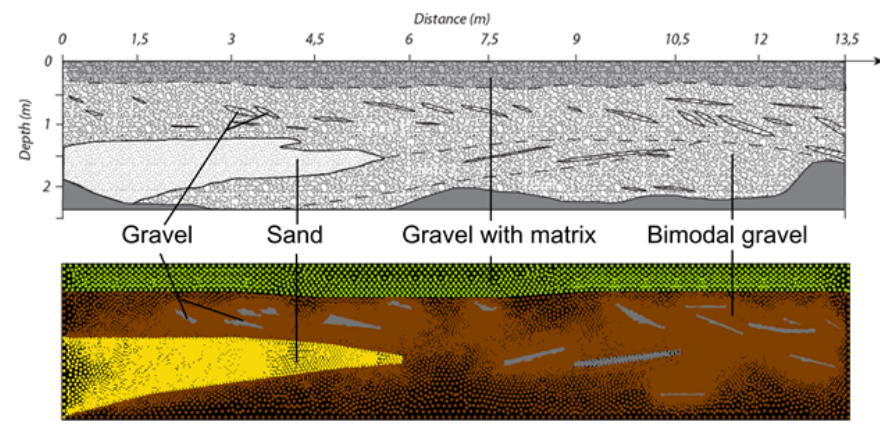

b) Hydraulic characteristic curves

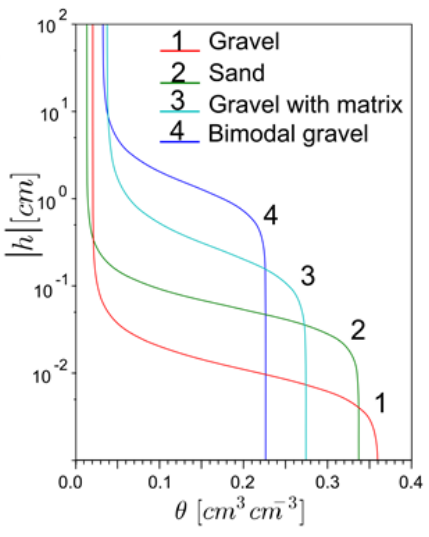

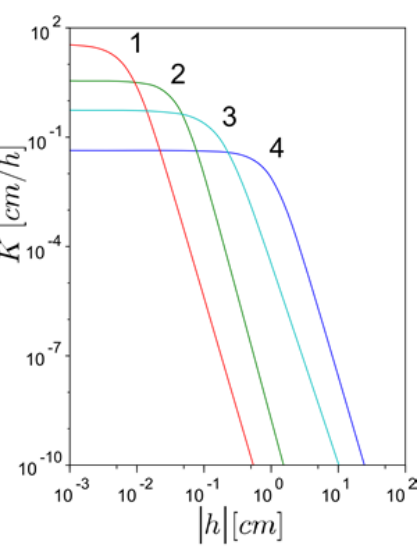

\section{c) Studied scenarios}

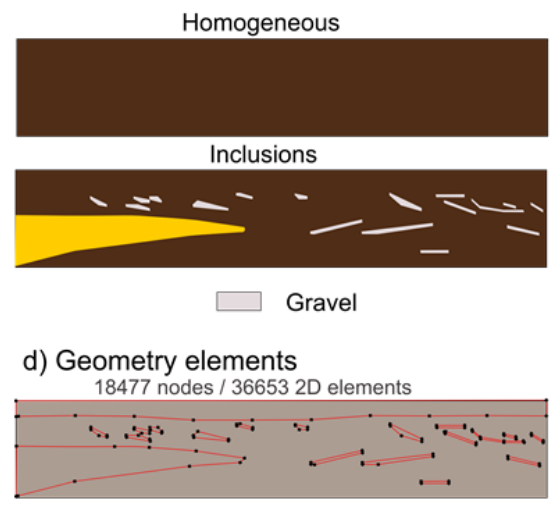

Layer

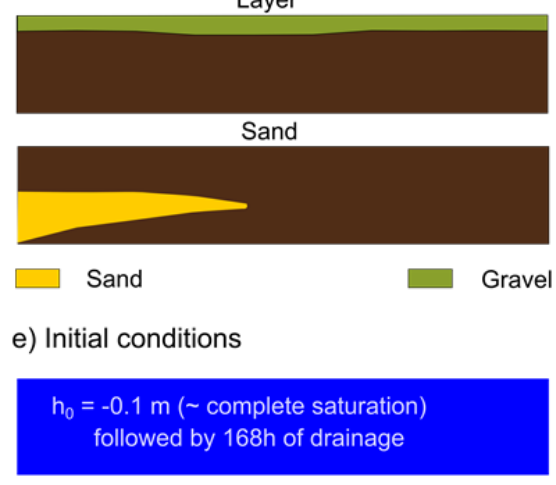

All (heterogeneities)

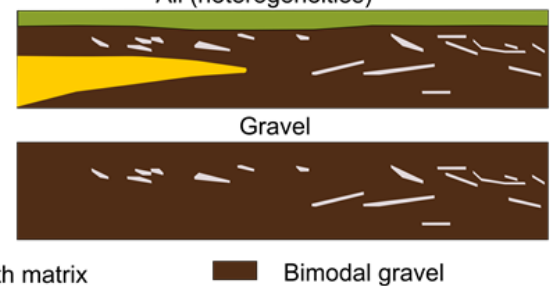

f) Boundary conditions

Fig. 1. Graphical representation of evaluated scenarios: (a) Observed heterogeneity in a two-dimensional transect, (b) Soil hydraulic characteristic curves, (c) Evaluated scenarios with different types of heterogeneities.

Scenario 4, denoted as "Incls," additionally considered both sandy and matrix-free gravel inclusions. This scenario differs from Scenario 3 by not considering the surface layer. Additionally, Scenarios 5 and 6, denoted as "Sand" and "Gravel," alternatively considered either the sandy or matrixfree gravel inclusions, respectively. A comparison of results obtained for the homogeneous scenario (Scenario 1) with those for the heterogeneous scenarios (Scenarios 2 through 6) allows for the discrimination of separate effects of the surface layer and individual inclusions (sand lens, gravel lenses, and all lenses simultaneously) and of the overall effect of all heterogeneities together.

\section{Analysis of the numerical data}

The arrival of the water front at the lower boundary of the soil profile and the spatial variability of water fluxes at the steady state were compared between scenarios. To simplify the comparison, we defined both several characteristic times to quantify the impact of lithological heterogeneities on the arrival of the water front at the lower boundary, and dispersion indicators to characterize the spatial heterogeneity of the water flux field at steady state. The following characteristic times were defined (see the Result section for graphical illustration of these times): a) breakthrough time $\left(t_{b r}\right)$, when the flow rate at the bottom boundary starts increasing (a transition between the drainage phase and the arrival of the wetting front at the lower boundary), b) wetting front arrival time $\left(t_{w f}\right)$, when the flow rate reaches the average value between initial and final flow rates, and c) stabilization time $\left(t_{\text {stab }}\right)$, when the flow rate reaches a plateau approximately corresponding to the value of the flow rate imposed at the surface (i.e., the beginning of the steady state). The value of $t_{w f}$ can be considered as the average arrival time of the wetting front at the lower boundary, and the difference between stabilization and breakthrough times $(\Delta t=$ $\left.\left(t_{s t a b}-t_{b r}\right) / 2\right)$ can be viewed as an indicator for time dispersion around the averaged arrival time. These characteristic times can be viewed as measures of water residence time in the systems. The characteristic times allow for the quantification of the influence of different lithological heterogeneities on the flow patterns and their variation depending on applied flow rates.

In addition, the flow resistance of a system may also be a key parameter, and the effects of inclusions and layering may be important when the hydrological response of such deposits needs to be quantified. The flow resistance was derived below from the analysis of pressure head profiles at steady states. To quantify the effective hydraulic conductivity at the scale of a transect, we computed the hydraulic gradient over the entire transect from the average water pressure heads at the upper and lower boundaries. We then derived the effective hydraulic conductivity using the Buckingham-Darcy law:

$$
K_{e f f}=\frac{q L}{\left(L+\left(\bar{h}_{z=0}-\bar{h}_{z=L}\right)\right)}
$$

where $K_{\text {eff }}\left(\mathrm{L} \mathrm{T}^{-1}\right)$ is the effective hydraulic conductivity, $L$ is the depth of the profile $(\mathrm{L}), q\left(\mathrm{~L} \mathrm{~T}^{-1}\right)$ is the infiltration rate imposed at the surface, and $h_{z=0}(\mathrm{~L})$ and $h_{z=L}(\mathrm{~L})$ refer to the average water pressure heads at the surface and the lower boundary, respectively. The values of effective hydraulic conductivities were then compared between scenarios. 


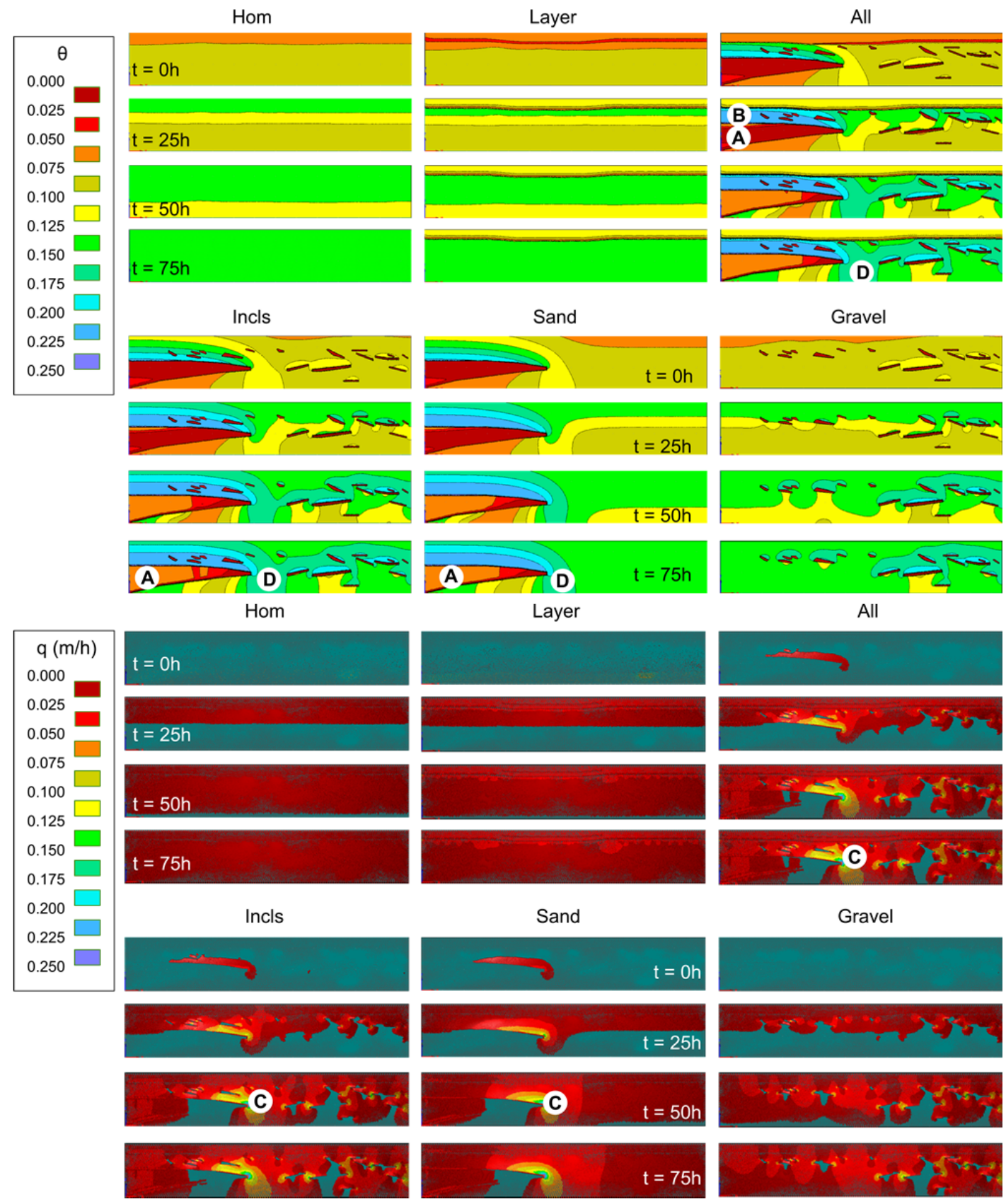

Fig. 2. Time evolution (at $0,25,50$, and $75 \mathrm{~h}$ ) of water contents (top) and water fluxes (bottom) for the six evaluated scenarios at the lowest flow rate $(0.0025 \mathrm{~m} / \mathrm{h})$. Capital letters in the figure are referred to in the text.

\section{RESULTS}

\section{Preferential flow at the lowest flow rate $(0.0025 \mathrm{~m} / \mathrm{h})$}

Simulated volumetric water contents and water fluxes are presented in Fig. 2 as a function of time for the first flow rate of $0.0025 \mathrm{~m} / \mathrm{h}$. Wetting fronts for the homogeneous and layered profiles are typically piston-like and horizontal. The water flux field is uniform with similar fluxes in the entire transect above the wetting front. In contrast, for all the other scenarios, wetting fronts have singular and complex shapes reflecting the locations of the various inclusions that water attempts to bypass. Water contents are lower in inclusions (e.g., letter A in Fig. 2), and water accumulates above inclusions (e.g., letter B in Fig. 2), which is a common capillary barrier effect. Water fluxes show that flow pathways are distorted and mostly develop between inclusions, leading to funneled flow. Locally, along preferential flow pathways, the water flux can increase more than ten times in comparison to the value imposed at the soil surface (e.g., letter C in Fig. 2., bottom).

Water fluxes at the lower boundary are depicted in Fig. 3a and the definition of related characteristic times is given in Fig. 3b. During the transient state, water fluxes at the lower boundary increase from a very low initial value (the end of the preceding draining phase) to the value of the flow rate imposed at the soil surface (Fig. 3a). The increase does not occur at the same time and depends on the scenario. There are two distinct responses. There is an earlier arrival of the wetting front for all heterogeneous scenarios that include the sand lens, and a late arrival of the wetting front for all other scenarios (i.e., without the sand lens) (Fig. 3a). This is reflected by lower values of breakthrough and arrival times (Figs. 3c and 3e) for scenarios with the sand lens. The stabilization time and time dispersion are increased by any kind of lithological heterogeneity, except for the scenario with the surface layer that has no clear impact 

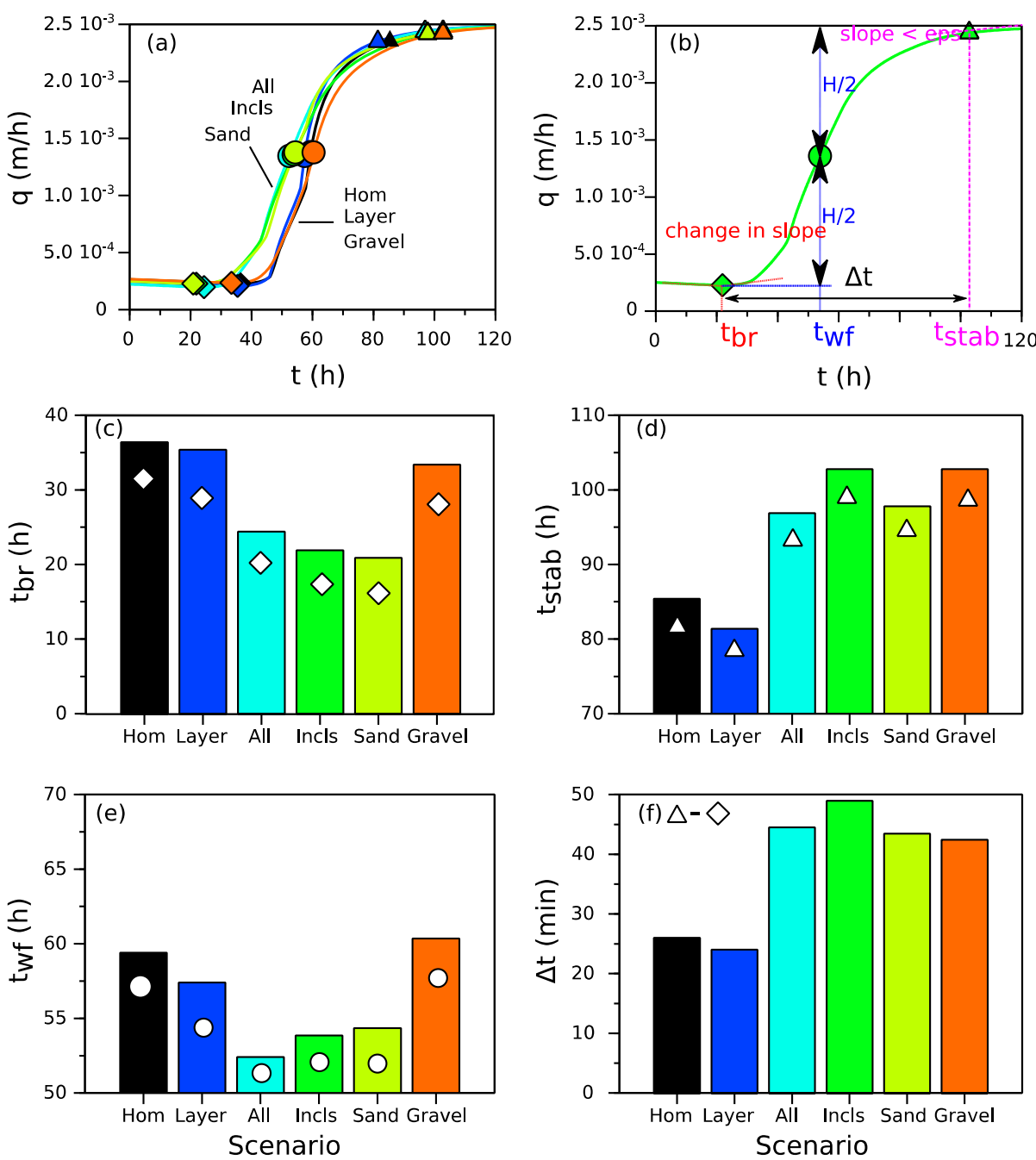

Fig. 3. (a) Water fluxes at the bottom boundary, (b) definition of characteristic times, (c) breakthrough times $t_{b r}$, (d) stabilisation times $t_{s t a b}$, (e) wetting front arrival times $t_{w f}$, and (f) time dispersions $\Delta t$ for the six evaluated scenarios at the lowest flow rate $(0.0025 \mathrm{~m} / \mathrm{h})$.

in these characteristic times (Figs. 3d and 3f). It can be concluded that the surface layer has no significant effect on characteristic times, while the gravel inclusions increase the dispersion in arrival times, and the sand inclusion at the same time decreases and disperses arrival times.

The water flux field at steady state is shown for the scenario with all lithofacies in Fig. 4a. It is clear that the sand lens and the gravel lenses induce deviations in flow and behave as capillary barriers at this low flow rate. This has a clear impact on the flux spatial heterogeneity and horizontal distributions of water fluxes at all depths (Figs. 4b-g). Water fluxes are quite homogeneous for depths of 0 and $0.5 \mathrm{~m}$ for all scenarios. For depths larger than $1.5 \mathrm{~m}$, the effects of various inclusions become more important. The sand lens clearly produces both a decrease in water fluxes inside the sand lens and an increase of them at its right side due to flow diversion (e.g., letter A in Fig. 4f). The gravel inclusions produce clear oscillations in water fluxes at the same depth (e.g., letters $\mathrm{C}$ to $\mathrm{E}$ in Figs. $4 \mathrm{~d}-\mathrm{g}$ ). In the middle, the effects of one gravel lens and the sand lens overlap, leading to the superposition of respective effects (see letter B in Figs. $4 \mathrm{e}-\mathrm{g})$.

Coefficients of variation $C V_{q}$ (the standard deviation divided by the mean) were calculated for all water flux distributions both at different depths and for different scenarios (Figs. 4b-g) and then plotted as a function of depth in Fig. 4h. The coefficients of variation were also averaged to obtain a coefficient of variation at the transect scale and to define a global indicator of the flux spatial heterogeneity for different scenarios (Fig. 4i). Clearly, the highest spatial heterogeneity of water fluxes was obtained for the heterogeneous transect containing all lithofacies (Fig. 4i). The sand and gravel lenses cause a spatial variability in the water fluxes to a lesser extent. The surface layer has no effect on the spatial variability of the water fluxes, which are as homogeneous over the length of the transect as in the homogeneous transect.

The surface layer in our system does not seem to have an important effect either on water residence time in the system or water flux distributions. The sand lens triggers the main preferential flow pathway at its side, resulting in an increase in the spatial variability of water fluxes and at the same time, both a decrease in mean residence time and an increase in time dispersion. While the gravel inclusions have a substantial impact on the spatial heterogeneity of water fluxes, they only have a limited impact on water residence time in the system. The geometry of inclusions seems to be a key factor. Small inclusions, randomly distributed in the soil profile, will produce flow pathways that will bypass some inclusions before encountering others. Water will then be successively accelerated and slowed down along the flow pathways. This will result in similar residence times and a larger time dispersion than in the homogeneous profile, as observed in the simulation results presented in Fig. 3. 
(a) Steady state flow field

$\mathrm{q}(\mathrm{m} / \mathrm{h})$

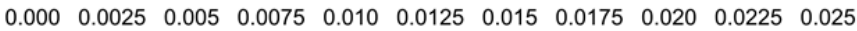
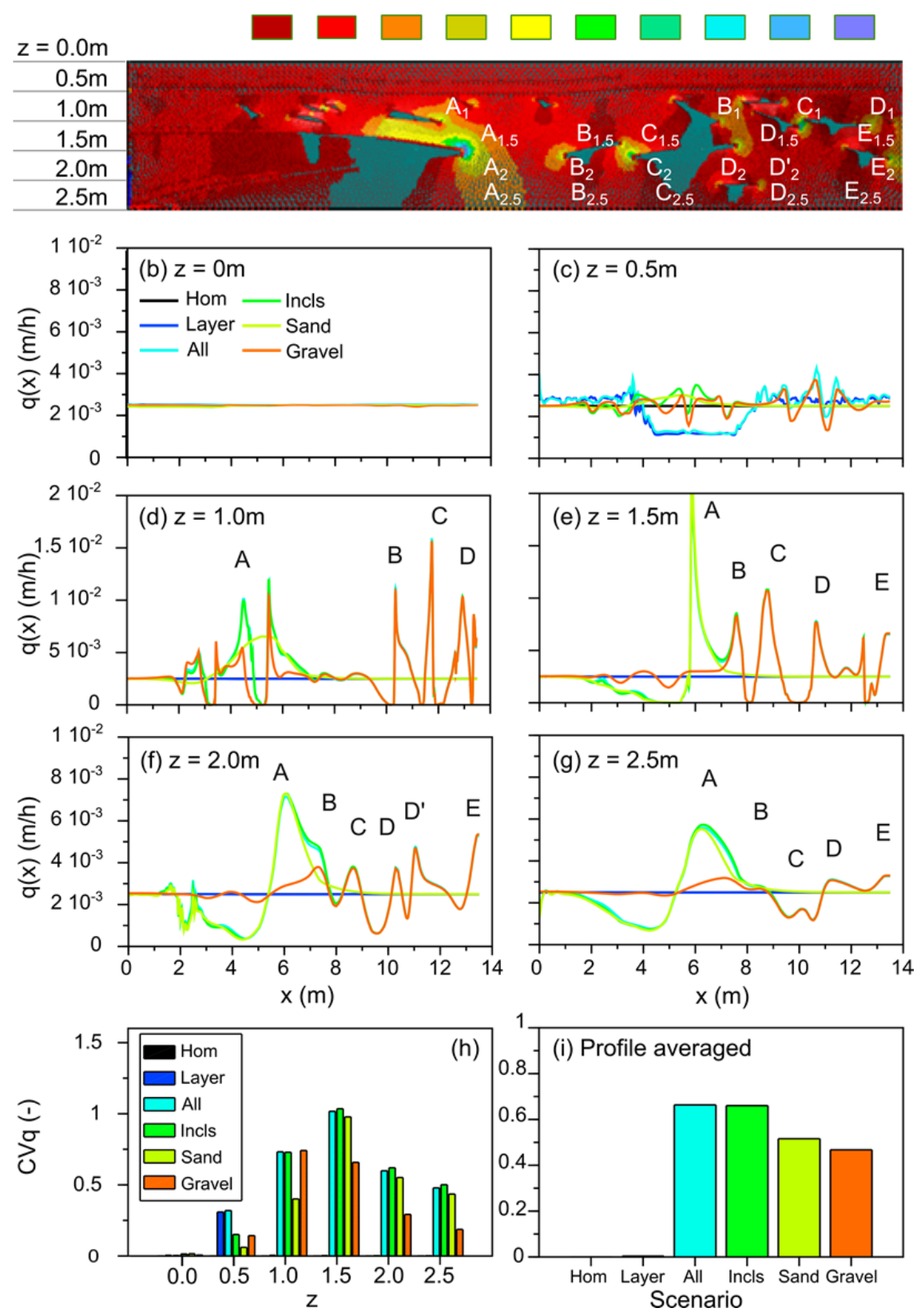

Fig. 4. (a) Water fluxes for the steady state flow conditions for a scenario with full heterogeneity at the lowest flow rate $(0.0025 \mathrm{~m} / \mathrm{h}),(\mathrm{b}-\mathrm{g})$ water flux profiles at different depths $\left(0,0.5,1.0,1.5,2.0,2.5 \mathrm{~m}\right.$, respectively), (h) corresponding coefficients of variation $C V_{q}$ at different depths, (i) profile averaged values of coefficients of variation $C V_{q}$ (i).

\section{Preferential flow at the highest flow rate $(0.04 \mathrm{~m} / \mathrm{h})$}

In comparison to the simulations with the lowest flow rate, the differences in the movement of the wetting fronts between the homogeneous and heterogeneous scenarios at the highest evaluated flow rate are smaller during the transient state. In all the scenarios, wetting fronts are more horizontal, and water infiltration resembles more a piston-like process. For instance, at 4 and $6 \mathrm{~h}$, wetting fronts are almost horizontal and indicate a more piston-like and less funneled flow than observed at the lower flow rate (e.g., letter A in Fig. 5 versus letter D in Fig. 2). However, in the scenarios that consider the sand lens, wetting fronts are curved below the sand lens, indicating that water moves faster within the sand lens than in the rest of the profile (e.g., letter B in Fig. 5). This indicates a preferential water infiltration within the body of the sand lens. Similar conclusions can be obtained from water flux fields (Fig. 5c).

Wetting fronts arrive at the lower boundary earlier in all scenarios that consider the sand lens than in the scenarios without the sand lens, irrespective of what other heterogeneities are included (Fig. 5b). The wetting fronts arrive later in scenarios with the homogeneous or layered soil profiles. The scenario that considers only the gravel inclusions produces intermediate arrival time. Similar trends can be observed with respect to characteristic times. All the scenarios containing the sand lens have shorter wetting front arrival times and breakthrough times (Table 1). The scenarios with homogeneous and layered soil profiles exhibit longer characteristic times, while the scenario with the gravel inclusions produces intermediate values. The earlier arrival of wetting fronts at the lower boundary in scenarios 
The role of heterogeneous lithology in a glaciofluvial deposit on unsaturated preferential flow - a numerical study

Table 1. Characteristic times quantifying the impact of lithological heterogeneities on the arrival of the water front at the lower boundary, i.e., $t_{b r}$ - breakthrough time, $t_{s t a b}$ - stabilization time, $t_{w f}$ - wetting front arrival time, $\Delta t=\left(t_{s t a b}-t_{b r}\right) / 2$, and the coefficients of variation for water flux distributions at the lower boundary, $C V_{q}$, at the lowest and the highest imposed flow rates.

\begin{tabular}{l|cccccc}
\hline Variable & Hom & Layer & All & Incls & Sand & Gravel \\
\hline & \multicolumn{7}{c}{ The lowest flow rate $(0.0025 \mathrm{~m} / \mathrm{h})$} \\
\hline$t_{b r}(\mathrm{~h})$ & 36.4 & 35.4 & 24.4 & 21.9 & 20.9 & 33.4 \\
$t_{\text {stab }}(\mathrm{h})$ & 85.4 & 81.4 & 96.9 & 102.2 & 198.7 & 198.2 \\
$t_{w f}(\mathrm{~h})$ & 59.4 & 57.4 & 52.4 & 53.4 & 54.4 & 60.4 \\
$\Delta t(\mathrm{~h})$ & 24.5 & 23 & 36.3 & 40.5 & 38.5 & 34.7 \\
$C V_{q}(-)$ & $0.02 \%$ & $0.37 \%$ & $66.4 \%$ & $66.0 \%$ & $51.6 \%$ & $46.7 \%$ \\
\hline & 6.70 & 6.65 & 5.41 & 4.88 & 4.89 & 5.92 \\
\hline$t_{b r}(\mathrm{~h})$ & 11.10 & 11.15 & 10.10 & 9.80 & 10.85 & 10.35 \\
$t_{s t a b}(\mathrm{~h})$ & 59.4 & 57.4 & 52.4 & 53.4 & 54.4 & 60.4 \\
$t_{w f}(\mathrm{~h})$ & 2.20 & 2.25 & 2.35 & 2.46 & 2.98 & 2.22 \\
$\Delta t(\mathrm{~h})$ & $0.01 \%$ & $0.08 \%$ & $12.0 \%$ & $8.97 \%$ & $3.16 \%$ & $9.79 \%$ \\
$C V_{q}(-)$ & \multicolumn{7}{c}{ The highest flow rate $(0.04 \mathrm{~m} / \mathrm{h})$} \\
\hline
\end{tabular}

(a) Water contents

\begin{tabular}{|c|c|}
\hline$\theta$ & \\
\hline 0.000 & \\
\hline 0.025 & \\
\hline 0.050 & \\
\hline 0.075 & \\
\hline 0.100 & \\
\hline 0.125 & \\
\hline 0.150 & \\
\hline 0.175 & \\
\hline 0.200 & \\
\hline 0.225 & \\
\hline 0.250 & \\
\hline
\end{tabular}

$t=2 h$
$t=4 h$
$t=6 h$
$t=8 h$
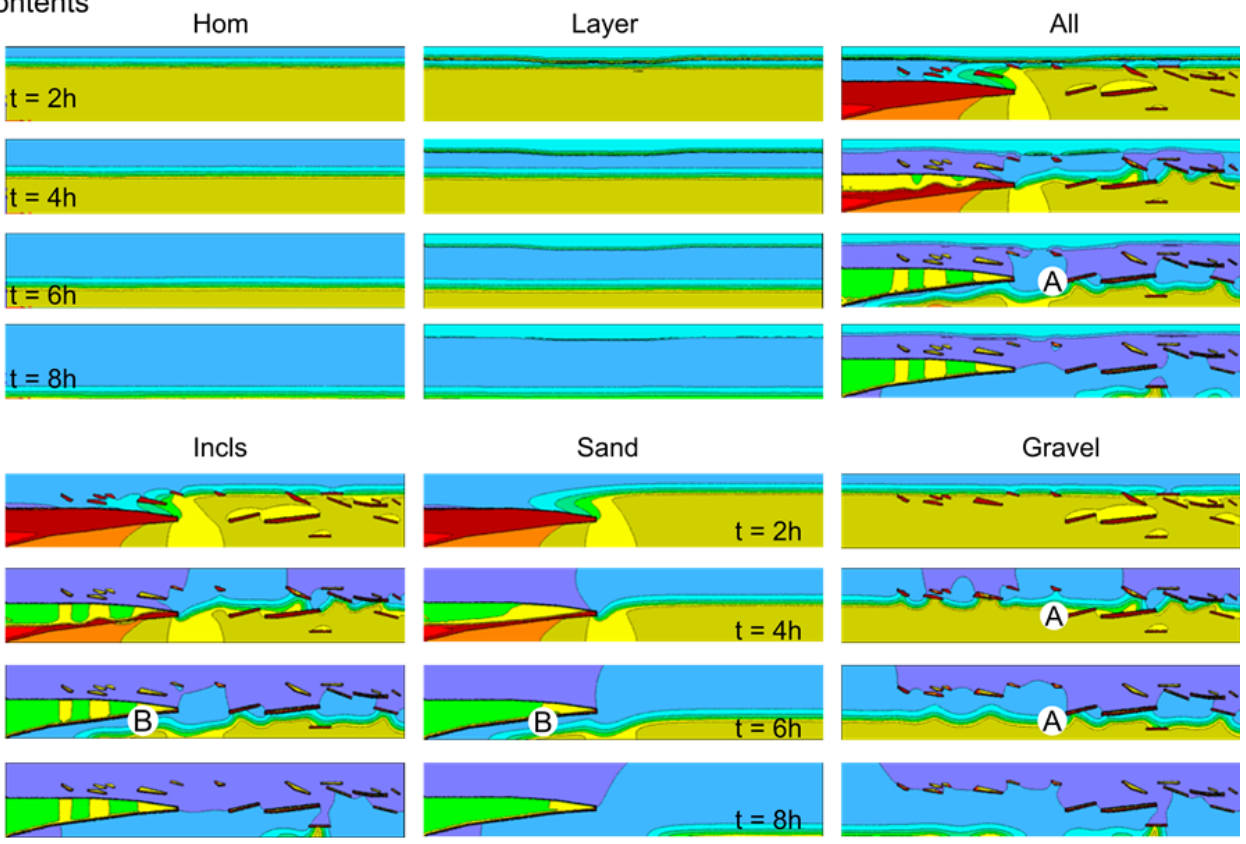

(b) Fluxes at lower BC

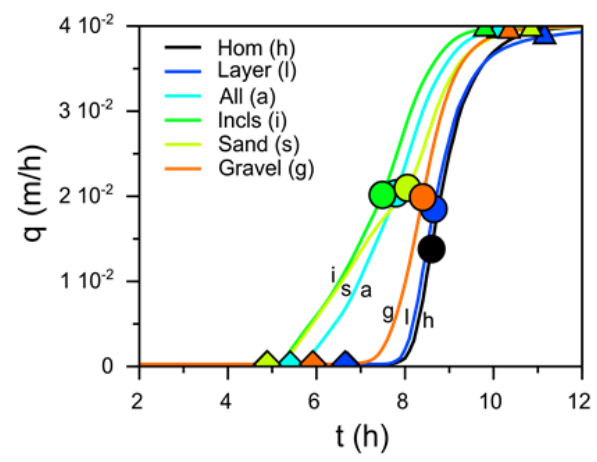

(c) Velocity field at steady state Hom
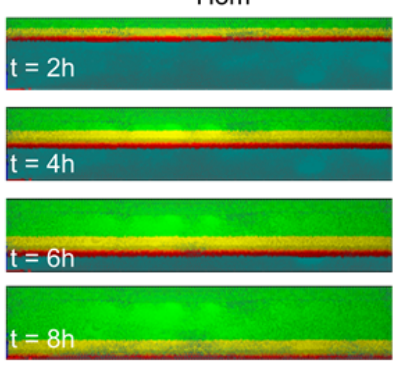

$q(\mathrm{~m} / \mathrm{h})$
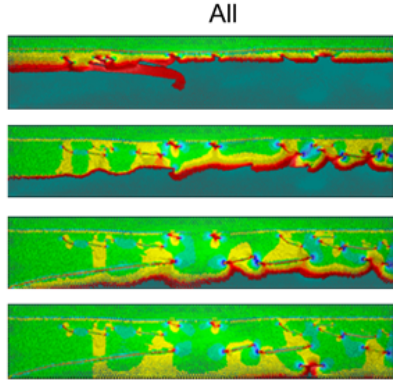

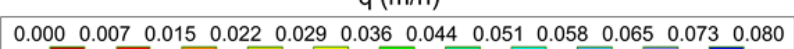

Fig. 5. Time evolution (at $0,25,50$, and $75 \mathrm{~h}$ ) for the six scenarios of water contents (a), water fluxes at the lower boundary (b), and velocity fields at steady state for the homogeneous and fully heterogeneous scenarios at the highest flow rate $(0.04 \mathrm{~m} / \mathrm{h})$. Capital letters in the figure are referred to in the text.

with the sand lens is attributed to the enhancement of downward flow within the sand lens. All the scenarios exhibit similar values with respect to time dispersion (Table 1), indicating that the wetting fronts simply moved backward or forward along a time axis with no change in dispersion around the average arrival time. Although the time interval during which water fluxes increase appears to be narrower in scenarios with the homogeneous or layered soil profiles (Fig. 5b), this is not 
(a) Steady state at low flow rate
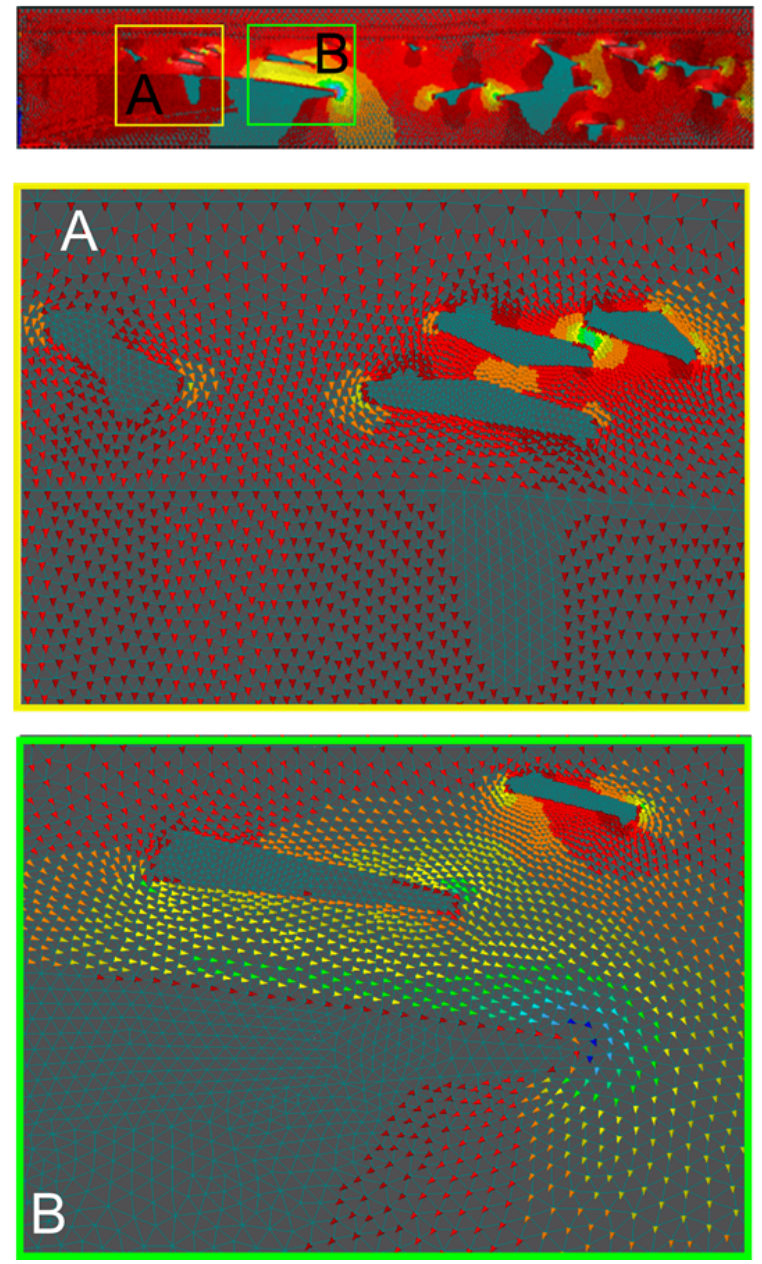

(b) Steady state at high flow rate
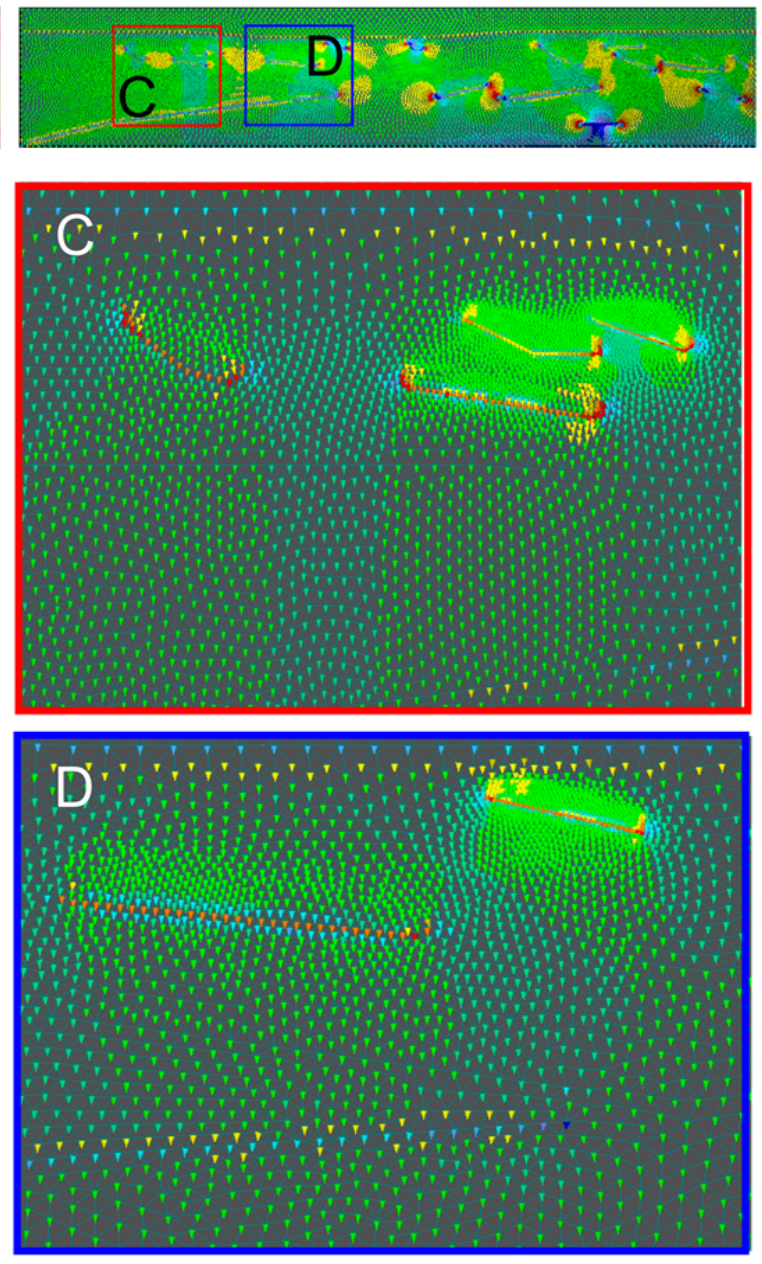

Fig. 6. Comparison of flow patterns in the vicinity of the gravel and sand lenses at the two extreme flow rates $(0.0025 \mathrm{~m} / \mathrm{h}$ (left) versus 0.04 $\mathrm{m} / \mathrm{h}$ (right)). The color scales in (a) and (b) are the same as in Fig. 2 and 5, respectively.

reflected in the values of time dispersion $\Delta t$, which does not reflect this observation (Table 1).Scenarios with the surface soil layer and both sand and gravel inclusions showed that these heterogeneities have only a slight impact on the water flux field at steady state at the largest evaluated flux (e.g., Fig. 5c and Fig. 6). The sand lens has lost its effect of a capillary barrier at this flux rate, as revealed by the fact that flow no longer avoids the sand lens (Fig. 6, letters $\mathrm{C}$ and $\mathrm{D}$ versus $\mathrm{A}$ and $\mathrm{B}$ ). In this case, the water pressure head and the corresponding hydraulic conductivity of the sand is high enough, compared to the surrounding bimodal gravel, to prevent the capillary barrier effect and to allow water to directly enter the sand lens. The sand lens, rather than diverting flow as occurred at low fluxes, preferentially conducts water through its body at higher fluxes (even more visible in the left part of the lens). On the other hand, the gravel lenses continue to act as capillary barriers, but to a smaller extent than at the lowest flow rate (Fig. 6, letters $\mathrm{C}$ and $\mathrm{D}$ versus $\mathrm{A}$ and $\mathrm{B}$ ). This change in the flow pattern also has an impact on the horizontal distribution of water fluxes at the scale of the transect (Fig. 5c). Distributions of water fluxes are relatively uniform in the scenario with only the sand lens and in the homogeneous and layered scenarios. The sand lens no longer distorts flow pathways. The scenarios containing the gravel lenses exhibit more water flux variations. This is confirmed by the values of $C V_{q}$ (Table 1). This last parameter indicates that the flow field appears more heterogeneous for all scenarios that consider gravel inclusions (Table 1, scenarios All, Incls, and Gravel, The highest flow rate). The numerical simulations performed at the highest flow rate indicate that sand loses its capillary barrier effect and that gravel remains the sole source of spatial heterogeneity. The spatial heterogeneity of flow is smaller at the higher flow rate than at the smaller flow rate at the spatial scale of these simulations, with values of the coefficients of variation around $10 \%$ at a flux of $0.04 \mathrm{~m} / \mathrm{h}$, versus $60 \%$ at a flux of $0.0025 \mathrm{~m} / \mathrm{h}$ (Table 1 ).

It can be concluded that at the highest flow rate, the capillary barrier effect disappears for the sand lens and decreases for the gravel lenses. An increase in the applied surface flow rate lessens the capillary barrier effect because it increases the pressure heads in the soil profile and reverses the difference in corresponding hydraulic conductivities of the lenses and surrounding soil, which actually favors the moistening of inclusions. Consequently, flow becomes much more homogeneous and water residence times are less dispersed at the scale of simulations. The sand lens conducts a part of infiltrating water through its body, leading to a lower residence time in any scenario that contains the sand lens. In contrast, a similar decrease in residence time was due to preferential funneled flow at the lowest flow rate. The results of these simulations demonstrate that flow heterogeneity is boosted at the lowest flow rate and that the lithological heterogeneity loses its potential for disturbing flow at the highest flow rate. 

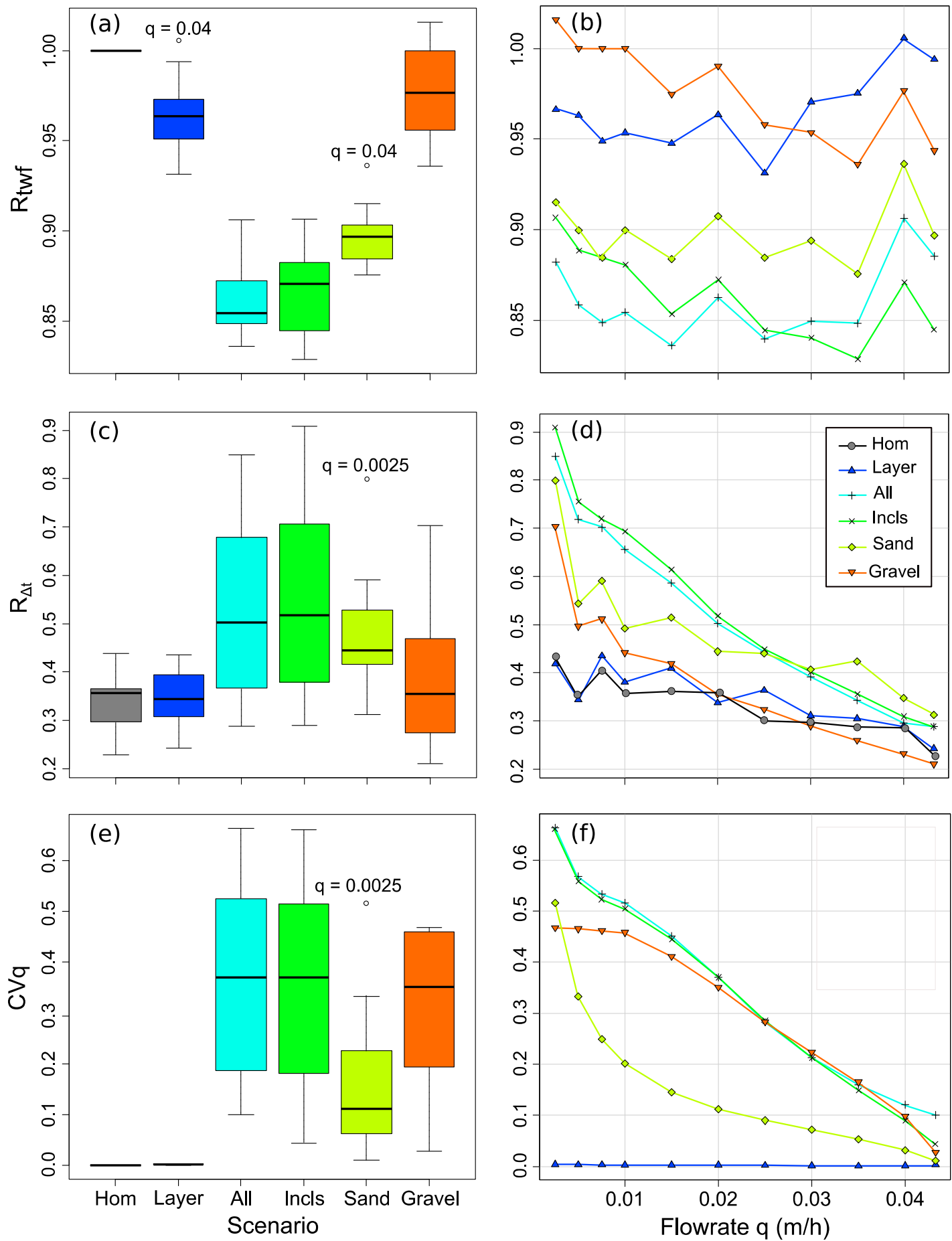

Fig. 7. Time enhancement $\left(R_{t w f}\right)$ as a function of the lithological heterogeneity (a) and the flow rate (b), dimensionless time dispersion $\left(R_{\Delta t}\right)$ as a function of the lithological heterogeneity (c) and the flow rate (d), and the coefficient of variation $\left(C V_{q}\right)$ for water fluxes as a function of the lithological heterogeneity (e) and the flow rate (f).

\section{Preferential flow as a function of flow rate - at intermediate fluxes}

The effect of lithological heterogeneities on flow is further investigated as a function of flow rates. Fig. 7 depicts characteristic times in the form of dimensionless indicators: (i) time enhancement $\left(R_{t w f}\right)$, which is defined as the arrival time of a wetting front $\left(t_{w f}\right)$ for a particular scenario divided by a corresponding value for the homogeneous scenario, (ii) the relative time dispersion $\left(R_{\Delta t}\right)$, which is defined as the time dispersion $(\Delta t)$ divided by the arrival time of the wetting front $\left(t_{w f}\right)$, and (iii) the coefficient of variation for the spatial heterogeneity of water fluxes at the transect scale $\left(C V_{q}\right)$. These parameters are shown as a function of lithological heterogeneities (Fig. 7, left side) and flow rates imposed at the soil surface (Fig. 7, right side).

With respect to the role of lithofacies, the main trends become apparent when results for all flow rates are simultaneously evaluated. The surface layer alone has an insignificant effect on water fluxes, which is similar to the homogeneous system (Figs. 7a, c, e), indicating that flow homogeneity is similar in both systems. The gravel lenses only have a small effect on time enhancement (Fig. 7a) and relative time dispersion (Fig. 7c), 
but a significant effect on flow spatial heterogeneity (Fig. 7e). Despite their strong effect at the local scale (inducing funneled flow), they have no clear effect at the transect scale. This is the result of a random distribution of inclusions that distort flow pathways more than they boost downward preferential flow. In contrast, the sand lens has a significant effect on time enhancement (Fig. 7a) and relative time dispersion (Fig. 7c). It also significantly affects the spatial heterogeneity of flow, but to a lesser extent than the gravel lenses (Fig. 7e). The sand inclusion induces a more structured preferential flow pattern, resulting in a more significant effect on water residence time at the transect scale. In other words, the geometry and the characteristic length of inclusions are the key parameters at the transect scale.

The impact of each lithological heterogeneity also depends on the flow rate. This can be demonstrated by comparing the effects of the sand and gravel lenses at the low and high flow rates of 0.0025 and $0.04 \mathrm{~m} / \mathrm{h}$, respectively. The gravel lenses lose their capillary barrier effect with an increase in the flow rate. The sand lens even transforms from a capillary barrier to a more conductive porous media. This shift in the hydraulic behavior is reached at a threshold flux value of $0.03 \mathrm{~m} / \mathrm{h}$. For the sand lens, there is no visible trend in time enhancement (Fig. 7b, Sand). The sand lens boosts the downward movement of the wetting front by creating preferential flow pathways at flow rates lower than $0.03 \mathrm{~m} / \mathrm{h}$ or by conducting water through its body at flow rates higher than $0.03 \mathrm{~m} / \mathrm{h}$. However, in all cases, the effect on the wetting front arrival is roughly the same (Fig. 7b, Sand). For the gravel lenses, the enhancement of the downward movement of the wetting fronts is more important at larger flow rates (Fig. 7b, Gravel). Both sand and gravel inclusions lose their effect on time dispersion with increasing flow rates, probably as a result of diminishing capillary barrier effects (Fig. 7d, Gravel or Sand). The same conclusion can be made for spatial flow variability, which decreases when the flow rate is increased (Fig. 7f). An increase in the flow rate reduces spatial flow variability to the level observed for the scenario with the homogeneous profile (Fig. 7f, heterogeneous scenarios versus Hom). Flow clearly becomes much more homogeneous when the flow rate is increased. Given a gradual decrease of relative time dispersion (Fig. 7d) and spatial flux heterogeneity (Fig. 7f) with an increase in the flow rate, it can be concluded that the shift in the flow regime (homogeneous versus heterogeneous) is continuous.

The homogenization of flow with the flow rate may be counterintuitive. It is usually assumed that higher flow rates and thus higher water pressure heads in heterogeneous soils will activate flow through zones with higher saturated hydraulic conductivities (Birkholzer and Tsang, 1997; Vogel et al., 2000). This is indeed often the case for soils with macropores, fractures, or cracks (Gerke and van Genuchten, 1996). In such cases, preferential flow is usually observed under conditions with high surface pressure heads, such as under ponded conditions at the soil surface (e.g., Gupta et al., 1999). In the studied deposit, the lithofacies with very high saturated hydraulic conductivities, in particular the gravel lenses, form inclusions that do not constitute a continuous network. As a result, water cannot flow in a well-connected network, bypassing the soil matrix and moving quickly from the soil surface to the bottom of the profile, which explains why flow remains mostly homogeneous under saturated conditions and high flow rates. In contrast, the main source of preferential flow in the studied deposit is linked to the capillary barrier effects and is thus more apparent at low flow rates under unsaturated conditions. Under these conditions, gravel lenses act as capillary barriers, thus triggering funneled flow.
However, their impact remains local, as a result of the small characteristic lengths of these inclusions. The sand lens also induces funneled flow. However, since its characteristic length is larger, the sand lens induces a flow deviation large enough to lead to funneled flow without a real bypass of the soil matrix.

The combination of different lithofacies does not alter the contribution of individual lithofacies. The spatial flow heterogeneity seems to be induced mainly by gravel at the local scale. Indeed, the values of $C V_{q}$ for the scenarios involving both gravel and sand lenses have similar $C V_{q}$ values as the scenario containing only the gravel inclusions (Fig. 7e, All and Incls versus Gravel). In contrast, the scenarios 'Incls' and 'All' exhibit similar values of time enhancement as the scenario with the sand lens alone (Fig. 7a). In other words, the sand lens is the main lithofacies contributing to the enhancement of the downward movement of the wetting fronts at this spatial scale, even when the gravel lenses are included. The effects of the sand and gravel lens on time dispersion are additive. Indeed, the relative time dispersion is higher for the scenario that considers all the lenses compared to the scenario that considers only the sand lens (Fig. 7c, All and Incls versus Gravel).

Finally, the addition of the surface layer does not change either spatial flux variability, time enhancement, or time dispersion (Fig. 7a, Fig. 7c, Fig. 7e, All versus Incls). It is interesting to note that the addition of a surface layer does not change flow patterns in lower horizons and does not affect flow homogeneity. Under other circumstances, several authors found a significant effect on flow homogeneity from the included soil layers (e.g., Lamy et al., 2013; Lassabatere et al., 2004). These authors showed that the inclusion of a geotextile into heterogeneous soils or soils containing macropores could interrupt preferential flow. However, these layers were placed in the middle of highly conductive zones (e.g., macropores) and had a lower hydraulic conductivity than the conductive zones. In the studied deposit, the surface layer is located above the zones where preferential flow develops and does not have necessarily a lower hydraulic conductivity, depending on the value of flow rate imposed at surface (Fig. 1).

\section{Influence of lithological heterogeneities on flow resistance}

The results presented above give some insight on the effects of heterogeneous lithology on flow patterns, heterogeneity of water fluxes, and wetting front arrival times. The analysis of numerically simulated pressure head profiles provides an insight on the effects of lithological heterogeneities on flow resistance. In the case of a homogenous soil profile, the steadystate water pressure head will be the same over the entire profile (Fig. 8a), resulting in a unit hydraulic gradient (Figs. $8 \mathrm{c}-\mathrm{d}$, Hom). Equation (3), along with the hypothesis of uniformity of water pressure heads between boundaries $\left(\bar{h}_{z=0} \approx \bar{h}_{z=L}\right)$, shows that $K_{\text {eff }}$ is equal to $q$. The steady-state water pressure head $h_{s s t}$ will be equal to the value that satisfies the equation $K\left(h_{s s t}\right)=q$, where $K(h)$ refers to the hydraulic conductivity function defined by equations (2), and $q$ is the applied surface flux. These assumptions are valid provided that the infiltration rate imposed at the soil surface does not exceed the saturated hydraulic conductivity, which is the case in this study. Otherwise, the steady-state infiltration rate will be equal to the saturated hydraulic conductivity and water runoff or ponding will occur at the soil surface When the transects are no longer homogeneous, the water pressure heads at boundaries will no longer be uniform (Fig. 8b). The sand and gravel inclusions cause a slight increase in the water pressure head at 
(a) $h_{\text {sst }}$ - Uniform section

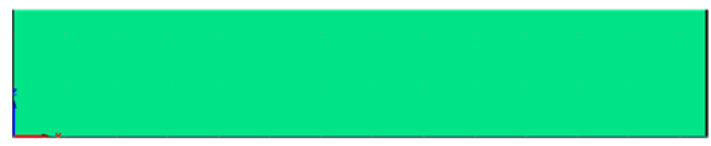

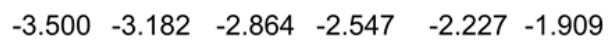
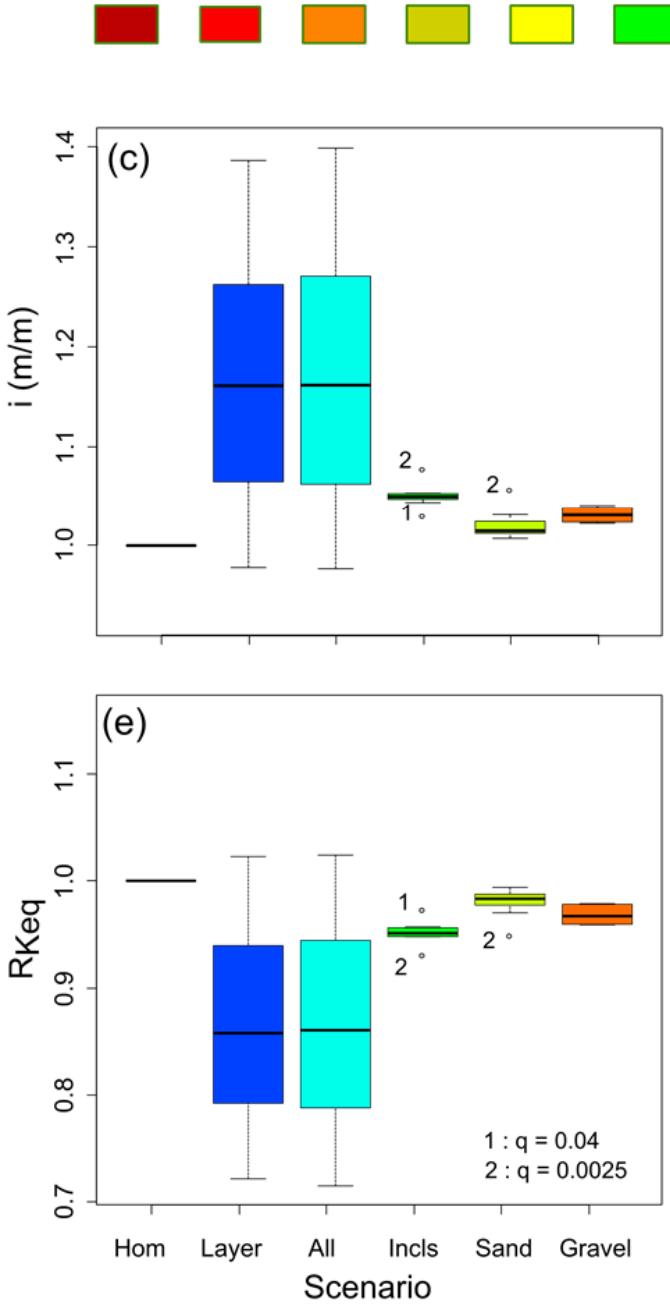

(b) $h_{\text {sst }}$ - Heterogeneous section

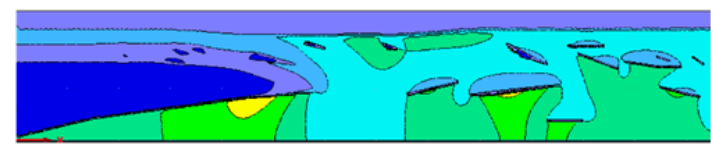

$\begin{array}{llllll}-1.591 & -1.273 & -0.955 & -0.636 & -0.318 & 0.000\end{array}$
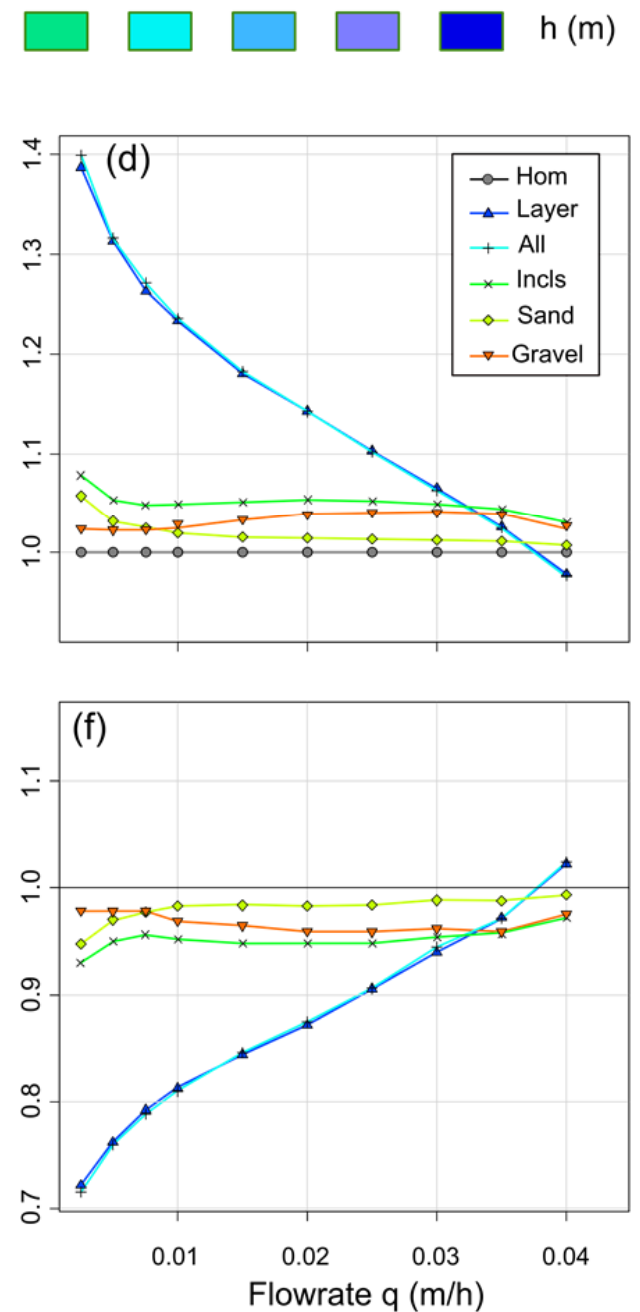

Fig. 8. The steady-state pressure head profiles for uniform (a) and heterogeneous (b) scenarios, the hydraulic gradient (i) as a function of scenarios (c) or flow rates (d), and the effective hydraulic conductivity of the heterogeneous scenarios divided by that of the homogeneous scenario as a function of scenarios (e) or flow rates (f).

the soil surface, resulting in hydraulic gradients larger than 1 for all flow rates imposed at the soil surface (Figs. 8c-d, Incls, Sand and Gravel). This indicates that the gravel and sand inclusions slightly impede flow and produce an effective hydraulic conductivity (profile-averaged) smaller than for the uniform profile (Figs. 8e-f, Incls, Sand and Gravel versus Hom). For the layered system, the hydraulic gradient depends strongly on the flow rate. For flow rates below a threshold value of $0.035 \mathrm{~m} / \mathrm{h}$, the effective hydraulic conductivity of the layered system is significantly lower than that of the homogeneous system (Figs. 8e-f, Layer versus Hom), producing a hydraulic gradient higher than 1 (Figs. 8c-d, Layer versus Hom). Otherwise, the effective hydraulic conductivity of the layered system exceeds that of the homogeneous system (Fig. 8f, Layer and $q=0.04$ ), leading to a hydraulic gradient below unity (Fig. 8d, Layer and $q=0.04$ ) and a lower water pressure head at the soil surface. This shift results from the fact that at low flow rates, i.e., at low water pressure heads, the surface layer has a smaller hydraulic conductivity than the predominant lithofacies, whereas at high flow rates close to saturation, the situation is opposite (Fig. 1b). Finally, for the fully heterogeneous soil profile, the effective hydraulic conductivity is mainly impacted by the surface layer. Indeed, similar values are found for the effective hydraulic conductivity and hydraulic gradients between the fully heterogeneous systems and the layered system (Figs. $8 \mathrm{c}-\mathrm{d}$ and Figs. 8e-f, Layer versus All). It can be concluded for studied systems that the surface layer is the predominant lithofacies that defines the effective hydraulic behavior of the deposit and that the gravel and sand inclusions only have a slight effect.

\section{CONCLUSIONS}

The results of this study support the following conclusions concerning the role of lithological heterogeneities on preferential flow in a strongly heterogeneous glaciofluvial 
deposit. The soil stratification mainly affects the equivalent permeability of the heterogeneous system. It increases the effective hydraulic conductivity for conditions close to saturation and lowers it for unsaturated conditions. It is expected that under saturated conditions, the surface layer, which is more conductive than underlying layers at saturation, should not adversely affect water infiltration at the soil surface or even increase water infiltration into the soil profile, thus reducing the risk of water runoff or ponding at the soil surface. Despite its effect on the effective hydraulic conductivity, the surface layer has no effect on flow pathways and flow heterogeneity.

Various sand or gravel inclusions only have a negligible effect on the effective hydraulic conductivity of the heterogeneous systems. Therefore, they should not affect infiltration of surface water or overall water fluxes. Inclusions will only impact the flow patterns (homogeneous or heterogeneous flow patterns

with channeling). For all inclusions, the main mechanism responsible for the establishment of preferential pathways is funneled flow, which is more a result of the lower hydraulic conductivities of inclusions than of the surrounding soil for a particular flow rate. The size of inclusions also has an important influence. Large inclusions (e.g., sandy lenses) will favor the development of well-organized and structured channeling, impacting water flow across the system. However, smaller inclusions will induce only local preferential flow, which will have less impact on the mass transfer at larger scales.

The degree of flow heterogeneity is also a function of the water content or the flow rate imposed at the surface. Dry conditions and low flow rates are the most conducive for the establishment of preferential flow for the systems evaluated in this study. In fact, these conditions cause the coarser lithofacies to be drained and to have a significant drop in hydraulic conductivity, which will cause capillary barrier phenomena in the system. Gravel inclusions have a hydraulic conductivity lower than the predominant lithofacies under all circumstances. However, this effect decreases for the sand lens when the flow rate increases. Therefore, the sand lens is transformed from a less permeable inclusion that diverts flow at lower fluxes to a more permeable inclusion that produces homogeneous flow at higher fluxes.

This numerical study clearly shows that the geometry of lithofacies will determine their impact on hydrological behavior of the transect. When the lithofacies constitute a continuous layer, they may more greatly impact the effective hydraulic conductivity of heterogeneous deposits. Conversely, the lithofacies that form small inclusions will more greatly impact flow heterogeneity, but are not expected to impact water fluxes or the overall water balance. It should be noted that these effects were observed for a specific case of one transect in a glaciofluvial deposit and for a set of specific hydraulic conditions. However, the methodology presented here could be applied to other transects with the spatial variability of lithological heterogeneities on the scale of the deposit (Coutinho et al., 2015; Goutaland et al., 2013) and to other types of heterogeneous deposits and soils. This study could also be expanded by investigating the dependency of the effects of lithological heterogeneities on rainfall event characteristics and on a succession of multiple rainfall events. Further research is needed to understand the effects of such modification of water flow on the fate of pollutants. However, inclusions are expected to have a dramatic impact on solute transport due to their effects on preferential flow (Winiarski et al., 2013). Indeed, it has often been demonstrated that preferential flow will decrease the contact between solute and reactive particles of the soils, thus reducing the potential for pollutant sorption into the soil (e.g. Köhne et al., 2009a, b; Lamy et al., 2013; Lassabatere et al., 2004, 2007). Inclusions may thus be a factor in enhancing the transport of pollutants towards groundwater, depending on their reactivity.

\section{REFERENCES}

Allaire, S.E., Roulier, S., Cessna, A.J., 2009. Quantifying preferential flow in soils: A review of different techniques. J. Hydrol., 378, 179-204.

Birkholzer, J., Tsang, C.-F., 1997. Solute channeling in unsaturated heterogeneous porous media. Water Resour. Res., 33, 2221-2238.

Clothier, B.E., Kirkham, M.B., McLean, J.E., 1992. In Situ Measurement of the Effective Transport Volume for Solute Moving Through Soil. Soil Sci. Soc. Am. J., 56, 733-736.

Coutinho, A.P., Lassabatere, L., Winiarski, T., Cabral, J.J.S.P., Antonino, A.C.D., Angulo-Jaramillo, R., 2015. Vadose Zone Heterogeneity Effect on Unsaturated Water Flow Modeling at Meso-Scale. J. Water Resour. Prot., 7, 353-368.

Gerke, H.H., van Genuchten, M.T., 1996. Macroscopic representation of structural geometry for simulating water and solute movement in dual-porosity media. Adv. Water Resour., 19, 343-357.

Goutaland, D., Winiarski, T., Dubé, J.-S., Bièvre, G., Buoncristiani, J.-F., Chouteau, M., Giroux, B., 2008. Hydrostratigraphic characterization of glaciofluvial deposits underlying an infiltration basin using ground penetrating radar. Vadose Zone J., 7, 194-207.

Goutaland, D., Winiarski, T., Lassabatere, L., Dubé, J.S., Angulo-Jaramillo, R., 2013. Sedimentary and hydraulic characterization of a heterogeneous glaciofluvial deposit: Application to the modeling of unsaturated flow. Eng. Geol., 166, 127-139. http://dx.doi.org/10.1016/j.enggeo.2013.09.006

Gupta, A., Destouni, G., Jensen, M.B., 1999. Modelling tritium and phosphorus transport by preferential flow in structured soil. J. Contam. Hydrol., 35, 389-407.

Hillel, D., 1998. Environmental Soil Physics: Fundamentals, Applications, and Environmental Considerations. Academic Press.

Jarvis, N., 2007. A review of non-equilibrium water flow and solute transport in soil macropores: Principles, controlling factors and consequences for water quality. Eur. J. Soil Sci., 58, 523-546.

Köhne, J.M., Köhne, S., Šimůnek, J., 2009a. A review of model applications for structured soils: a) Water flow and tracer transport. J. Contam. Hydrol., 104, 4-35.

Köhne, J.M., Köhne, S., Šimůnek, J., 2009b. A review of model applications for structured soils: b) Pesticide transport. J. Contam. Hydrol., 104, 36-60.

Lamy, E., Lassabatere, L., Bechet, B., Andrieu, H., 2013. Effect of a nonwoven geotextile on solute and colloid transport in porous media under both saturated and unsaturated conditions. Geotext. Geomembr., 36, 55-65. http://dx.doi.org/10.1016/j.geotexmem.2012.10.009

Lassabatere, L., Winiarski, T., Galvez-Cloutier, R., 2004. Retention of three heavy metals ( $\mathrm{Zn}, \mathrm{Pb}$, and $\mathrm{Cd})$ in a calcareous soil controlled by the modification of flow with geotextiles. Environ. Sci. Technol., 38, 4215-4221. DOI: 10.1021/es035029s.

Lassabatere, L., Angulo-Jaramillo, R., Soria Ugalde, J.M., Cuenca, R., Braud, I., Haverkamp, R., 2006. Beerkan 
estimation of soil transfer parameters through infiltration exexperiments-BEST. Soil Sci. Soc. Am. J., 70, 521-532.

Lassabatere, L., Spadini, L., Delolme, C., Février, L., Galvez-Cloutier, R., Winiarski, T., 2007. Concomitant $\mathrm{Zn}-\mathrm{Cd}$ and $\mathrm{Pb}$ retention in a carbonated fluvio-glacial deposit under both static and dynamic conditions. Chemosphere, 69, 1499-1508. http://dx.doi.org/10.1016/j.chemosphere.2007.04.053

Lassabatere, L., Angulo-Jaramillo, R., Goutaland, D., Letellier, L., Gaudet, J.P., Winiarski, T., Delolme, C., 2010. Effect of the settlement of sediments on water infiltration in two urban infiltration basins. Geoderma, 156, 316-325. http://dx.doi.org/10.1016/j.geoderma.2010.02.031

Lassabatere, L., Yilmaz, D., Peyrard, X., Peyneau, P.E., Lenoir, T., Šimůnek, J., Angulo-Jaramillo, R., 2014. New analytical model for cumulative infiltration into dual-permeability soils. Vadose Zone J., 13. DOI: 10.2136/vzj2013.10.0181

Mualem, Y., 1976. A new model for predicting the hydraulic conductivity of unsaturated porous media. Water Resour. Res., 12, 513-522.

Šimůnek, J., van Genuchten, M.T., 2008. Modeling nonequilibrium flow and transport processes using HYDRUS. Vadose Zone J., 7, 782-797.

Šimůnek, J., Jarvis, N.J., van Genuchten, M.T., Gärdenäs, A., 2003. Review and comparison of models for describing nonequilibrium and preferential flow and transport in the vadose zone. J. Hydrol., 272, 14-35.

Šimůnek, J., van Genuchten, M.T., Šejna, M., 2008. Development and applications of the HYDRUS and
STANMOD software packages and related codes. Vadose Zone J., 7, 587-600.

Šimůnek, J., van Genuchten, M.T., Šejna, M., 2016. Recent developments and applications of the HYDRUS computer software packages. Vadose Zone J., 15, 7, pp. 25, DOI: 10.2136/vzj2016.04.0033

van Genuchten, M.T., 1980. A closed-form equation for predicting the hydraulic conductivity of unsaturated soils. Soil Sci. Soc. Am. J., 44, 892-898.

Vogel, T., Gerke, H.H., Zhang, R., van Genuchten, M.T., 2000. Modeling flow and transport in a two-dimensional dualpermeability system with spatially variable hydraulic properties. J. Hydrol., 238, 78-89.

Walter, M.T., Kim, J.-S., Steenhuis, T.S., Parlange, J.-Y., Heilig, A., Braddock, R.D., Selker, J.S., Boll, J., 2000. Funneled flow mechanisms in a sloping layered soil: Laboratory investigation. Water Resour. Res., 36, 841-849.

Winiarski, T., Bedell, J.-P., Delolme, C., Perrodin, Y., 2006. The impact of stormwater on a soil profile in an infiltration basin. Hydrogeol. J., 14, 1244-1251. DOI: 10.1007/s10040006-0073-9.

Winiarski, T., Lassabatere, L., Angulo-Jaramillo, R., Goutaland, D., 2013. Characterization of the heterogeneous flow and pollutant transfer in the unsaturated zone in the fluvio-glacial deposit. Procedia Environ. Sci., 19, 955-964.

Received 9 August 2016 Accepted 9 November 2016 